\title{
Doppler Mitral Inflow Variables Time Course After Treadmill Stress Echo with and Without Ischemic Response
}

\section{FABIJAN LULIĆ ( $\sim$ fabijan.lulic@kbc-zagreb.hr)}

University Hospital Centre Zagreb https://orcid.org/0000-0002-2823-8833

\section{ZDRAVKO VIRAG}

University of Zagreb Faculty of Mechanical Engineering and Naval Architecture: Sveuciliste u Zagrebu Fakultet Strojarstva i Brodogradnje

\section{Research Article}

Keywords: diastolic stress echocardiography, ischemia, E-wave, deceleration rate

Posted Date: January 11th, 2022

DOI: https://doi.org/10.21203/rs.3.rs-1217074/v1

License: (c) (i) This work is licensed under a Creative Commons Attribution 4.0 International License.

Read Full License 


\section{Abstract}

This study evaluated Doppler mitral inflow variables changes from rest to post-exercise among 104 subjects with and without echocardiographic evidence of ischemic response (IR) to exercise (63.9 \pm 11 years, $54 \%$ male, $32 \%$ with IR) who underwent a clinically indicated treadmill stress echo (TSE) test. The time from exercise cessation to imaging (TIME) was recorded. The changes (after TSE minus baseline values) in the peak E-wave velocity $(\Delta \mathrm{E})$ [34.2 vs. 24.2, $\mathrm{p}=0.024]$ and $\mathrm{E}$-wave deceleration rate $(\Delta \mathrm{DR})$ [348.0 vs. 225.7, $p=0.010$ ] were bigger in ischemic than in nonischemic subjects, while the changes in the peak A-wave velocity $(\Delta A)$ did not differ [7.9 vs. 15.0, $p=0.082$ ]. The correlations between Doppler variables and IR, TIME, and TIME*IR interaction were analyzed. We observed a significant interaction between TIME and IR regarding $\triangle \mathrm{E}$ and $\triangle \mathrm{DR}$. The differences in the regression line slopes of time courses for $\Delta \mathrm{E}$ and $\Delta \mathrm{DR}$ based on IR were significant: $\Delta \mathrm{E}(-0.09$ vs. $-8.17, \mathrm{p}=0.037)$ and $\Delta \mathrm{DR}(11.23$ vs. $-82.60, p=0.022$. Main findings: 1 . Time courses after exercise of $\Delta E$ and $\Delta D R$ in subjects with and without IR were different. 2. $\Delta \mathrm{E}$ and $\Delta \mathrm{DR}$ did not differ between subjects with and without IR at exercise cessation (TIME $=0$ ). 3. The simple main effect of ischemia on $\Delta E$ and $\triangle D R$ was significant at TIME of $\geq 3 \mathrm{~min}$. Divergent time courses of $\Delta \mathrm{E}$ and $\Delta \mathrm{DR}$ after exercise might be promising for detecting diastolic dysfunction caused by ischemia.

\section{Introduction}

Diastolic stress echocardiography has emerged during the last two decades to detect diastolic dysfunction. The Doppler mitral inflow pattern (DMIP) is associated with physiological factors ((the left ventricle (LV) relaxation rate and stiffness, the left atrial (LA) stiffness and contractility, filling volumes, diastolic filling time, mitral valve area and inertance $[5,24]$ that determine the diastolic oscillatory atrioventricular pressure gradient (AVPG). The corresponding constitutive equations define the LA and LV pressures in terms of stiffness, instantaneous volume, and probably the volume change rate. Knowing the time variation of the LA and LV pressures, by that the AVPGs, it is possible to calculate DMIP variables ((peak E-wave velocity (E), E-wave deceleration rate (DR), and peak A-wave velocity (A)). Inversely, obtaining values of crucial physiological parameters only from DMIP is impossible [18]. The number of pieces of information we can extract from the DMIP is too small to determine all unknowns.

\section{Physiological considerations:}

Strong LV relaxation, high LA pressure, and a compliant LA generate steep initial AVPGs, and tall E [11]. LV stiffness has a contrasting effect on E; generally, a stiff LV indirectly increases LA pressure, by that $E$ $[23,25]$. However, steep increase in LV pressure quickly overshoots the equilibrium AVPG and blocks further growth of the E-wave [26]. Simultaneous echocardiography-catheterization studies and mathematical modeling showed that $E$ is not a good predictor of LA pressure $[5,23-26,28]$. High filling volumes superimposed on stiff LV induce a steep increase in reverse AVPG that is positively associated with DR $[6,26]$. LV stiffness at the time of LA contraction is negatively associated, while HR and left atrial contractility are positively associated with $\mathrm{A}$. 


\section{Exercise physiology:}

During exercise, diastolic filling time shortens and filling volumes increase. LV relaxation rate and LA pressures adjust their values to increase AVPGs and stroke volumes, which leads to more restrictive DMIPs (higher $E, D R$, and $E / A$ ). Adequate relaxation requires quick detachment of calcium from actinmyosin filaments, and any event that suppresses this process will decelerate the relaxation. Until recently, the prevailing opinion was that the hallmark of normal diastolic function is the maintenance of normal LA pressure during exercise and that higher AVPG is predominantly achieved through higher LV relaxation rates [2]. However, recent studies have shown a substantial increase in LA pressure during exercise, even in middle-aged healthy individuals $[7,19,27]$. High filling volumes stretch the myocardium in the relaxation process, which slows down the LV relaxation rate and increases its duration $[10,14]$. Myocardial viscosity (ratio of LV pressure change and filling rate) possibly also comes into play $[8,13]$. The final result of these processes is the high apparent LV stiffness [17]. This phenomenon is more pronounced in the elderly because their pressure-volume curve moves to the right and operates at higher pressures $[3,14,22]$.

Some individuals have an ischemic response (IR) to exercise with a blunted increase of the LV relaxation rate [9], increased LV stiffness and LA pressures, and restrictive DMIP [7, 19, 27]. Ischemia induces diastolic dysfunction through ATP depletion, abnormal calcium handling, persistent actomyosin bridging, and active diastolic tone throughout diastole [15].

Not surprisingly, there are circumstances where DMIPs may be similar between individuals who have an IR to exercise versus those that do not. For example, nonischemic patients with a high LV relaxation rate and a modest increase in LA pressures and ischemic patients with a blunted increase in the LV relaxation rate and a substantial increase in LA pressures may have similar DMIPs. An infinite number of combinations of physiological parameter values can result in similar AVPGs and DMIPs. Therefore, it is uncertain whether DMIP changes during exercise are sufficient to differentiate between ischemic and nonischemic subjects.

This study tested the hypothesis that DMIP changes pre to post-exercise were more restrictive in subjects with an IR to acute exercise.

\section{Methods}

The subjects underwent a clinically indicated treadmill stress echo (TSE) test using Bruce protocol with Doppler studies of mitral inflow at rest (values denoted by an index of 1 ) and after exercise (an index of 2). All subjects provided verbal informed consent to participate in the study. The exclusion criteria were: patients with technical limitations in image acquisition, atrial fibrillation, left bundle branch block, moderate-to-severe mitral annular calcification, and valve disease. TSE was performed according to standard protocols by certified sonographers $[1,20]$. Commercially available ultrasound machines were used. Two-dimensional echocardiographic images were recorded at rest and after exercise in four standard views (parasternal long and short axis and apical four-chamber and two-chamber views) to 
determine the wall motion score index (WMSI). The heart was divided into 16 segments. Each segment was scored according to its motion and systolic thickening: $1=$ normal, $2=$ hypokinetic, $3=$ akinetic, $4=$ dyskinetic, and $5=$ aneurysmal. The WMSI is the result of dividing the sum of the scores by 16 . Any increase in WMSI after exercise was defined as IR. Therefore, we considered IR as a categorical variable.

After obtaining 2-D images, the patients underwent a pulsed Doppler study of mitral inflow, and the study was recorded. The recording speed was $100 \mathrm{~mm} / \mathrm{s}$. The sample volume was positioned at the tip of the mitral leaflets. The smallest sample size and lowest possible Doppler gain were used. We measured $E$, $\mathrm{DR}$, and $\mathrm{A}$ off-line in three consecutive beats and calculated their mean values. The second Doppler assessment was performed after exercise, waiting until the $E$ and $A$ waves separated from one another so that DR could be reliably determined. The time from exercise cessation to imaging was recorded (TIME) (1-6 min). Figure 1 shows an example of Doppler mitral inflow pattern.

\section{Statistical analysis:}

We used an alpha level of 0.05 throughout the statistical analysis. Demographic, exercise, and Doppler data were reported as means \pm SD for continuous variables and percentages for categorical variables. The data of each variable were divided into two groups depending on the appearance of the IR, the ischemic and nonischemic group. Levene's test for the homogeneity of variance was performed for all variables. Student's $t$-test was used to test the difference in the mean values between the two groups. After obtaining postexercise Doppler values, the changes (postexercise minus the baseline values) were calculated. $T$-test was applied to check if the changes significantly differed between the two groups. Multiple regression analysis was performed on $\triangle \mathrm{DR}$ and $\triangle \mathrm{E}$ to determine significant predictors. The forward selection principle was used with TIME, IR, and TIME*IR as an initial set of predictors. Because of a significant TIME*IR interaction, TIME was forced into the model. Next, we tested the effect of including age, sex, and each exercise variable on its own $p$-value and the model's explanatory power. To determine significant differences in the slopes of $\triangle E$ and $\triangle D R$ with respect to TIME between the two groups, multiple regression analysis was performed considering TIME, IR, and TIME*IR as independent variables. To test the significance of the simple main effect of ischemia on $\triangle \mathrm{DR}$ and $\triangle \mathrm{E}$ at each point in the TIME, a new variable (TIME $-\mathrm{T}_{\text {shift }}$ ) was introduced, and successive multiple regression analyses were performed while changing $T_{\text {shift }}$ from 0 to 6 min. A statistical package from Microsoft Excel and XLSTAT 2020 was used for all analyses.

\section{Results}

One hundred and four subjects (: $63.9 \pm 11$ years, $54 \%$ male) underwent clinically indicated TSE, with Doppler studies of mitral inflow performed at rest and after exercise.

The subjects were categorized into two groups depending on the appearance of ischemia, which was defined as an increase in the WMSI from pre to post-exercise. 
Table 1 presents the baseline summary statistics of DMIP variables, heart rate, age and sex. Ischemia developed in $33(32 \%)$ subjects. The ischemic subjects were older $[t(96)=-2.37, p=0.020]$ and predominantly males $[F(1,102)=5.03, p=0.027$. None of the baseline DMIP values or HR (denoted by an index of 1) differed significantly between the two groups: $\mathrm{E}_{1}, t(102)=-0.12, p=0.903 ; \mathrm{DR}_{1}, t(102)=-$ $0.02, p=0.981 ; \mathrm{A}_{1}, t(102)=-1.57, p=0.119 ; \mathrm{HR}_{1}, t(46)=-0.13, p=0.900$.

Table 2 presents the summary statistics of the exercise variables and changes (postexercise-baseline) in $E, D R$, and A. The duration of exercise $[t(102)=0.44, p=0.664$; peak HR: $t(102)=1.72, p=0.088]$ and $\operatorname{TIME}[t(102)=-0.57, p=0.572]$ were not statistically different between the two groups. $\Delta \mathrm{HR}$ was significantly higher in patients without ischemia [t(102) $=2.85, p=0.005]$.

The $\Delta \mathrm{E}[t(102)=-2.29, p=0.024]$ and $\Delta \mathrm{DR}[t(102)=-2.64, p=0.010]$ were significantly higher in the ischemic subjects than in the nonischemic subjects. The changes in A were not statistically different between the ischemic and nonischemic subjects $[t(47)=1.78, p=0.082]$.

Table 1

Baseline Summary Statistics of Doppler and Clinical Variables

\begin{tabular}{|llll|}
\hline & $\begin{array}{l}\text { Group 1 } \\
\text { nonischemics }\end{array}$ & $\begin{array}{l}\text { Group 2 } \\
\text { ischemics }\end{array}$ & p-value \\
\hline $\mathrm{N}$ & $71(68 \%)$ & $33(32 \%)$ & - \\
\hline Age, years & $62.5 \pm 12.0$ & $67.0 \pm 7.2$ & 0.020 \\
\hline Males & $33(47 \%)$ & $23(70 \%)$ & 0.027 \\
\hline $\mathrm{E}_{1}, \mathrm{~cm} / \mathrm{s}$ & $72.3 \pm 21.4$ & $72.8 \pm 21.4$ & 0.903 \\
\hline $\mathrm{A}_{1}, \mathrm{~cm} / \mathrm{s}$ & $68.2 \pm 17.5$ & $74.4 \pm 21.1$ & 0.119 \\
\hline $\mathrm{DR}$ & \\
\hline $\mathrm{HR}_{1}, \mathrm{~cm} / \mathrm{s}^{2}$ & $388.6 \pm 177.2$ & $389.5 \pm 194.8$ & 0.981 \\
\hline $\mathrm{Val}$ beat $/$ min & $61.3 \pm 8.5$ & $61.6 \pm 12.7$ & 0.900 \\
\hline
\end{tabular}

The $p$-value indicates the significance of the differences in the mean values between the two groups. $\mathrm{N}=$ number of subjects; $\mathrm{E}$ = E-wave peak velocity; $\mathrm{A}=\mathrm{A}$-wave peak velocity; $\mathrm{DR}=\mathrm{E}$-wave deceleration rate; $\mathrm{HR}$ $=$ heart rate. Index 1 denotes baseline values. 
Table 2

Summary Statistics of Exercise Variables and Changes (Postexercise - Baseline) in Doppler Variables

\begin{tabular}{|c|c|c|c|}
\hline & $\begin{array}{l}\text { Group } 1 \\
\text { nonischemics }\end{array}$ & $\begin{array}{l}\text { Group } 2 \\
\text { ischemics }\end{array}$ & $p$-value \\
\hline$\Delta \mathrm{E}\left(\mathrm{E}_{2}-\mathrm{E}_{1}\right), \mathrm{cm} / \mathrm{s}$ & $24.2 \pm 21.6$ & $34.2 \pm 19.4$ & 0.024 \\
\hline$\Delta \mathrm{A}\left(\mathrm{A}_{2}-\mathrm{A}_{1}\right), \mathrm{cm} / \mathrm{s}$ & $15.0 \pm 14.8$ & $7.9 \pm 20.9$ & 0.082 \\
\hline$\Delta \mathrm{DR}\left(\mathrm{DR}_{2}-\mathrm{DR}_{1}\right), \mathrm{cm} / \mathrm{s}^{2}$ & $225.7 \pm 234.5$ & $348.0 \pm 183.9$ & 0.010 \\
\hline Duration of exercise, min & $7.9 \pm 2.7$ & $7.7 \pm 2.5$ & 0.664 \\
\hline Peak HR, beats/min & $141.1 \pm 21.7$ & $133.7 \pm 17.0$ & 0.088 \\
\hline$\Delta \mathrm{HR}\left(\mathrm{HR}_{2}-\mathrm{HR}_{1}\right)$, beats/min & $26.3 \pm 10.7$ & $19.5 \pm 12.9$ & 0.005 \\
\hline TIME, min & $2.9 \pm 1.1$ & $3.1 \pm 1.1$ & 0.572 \\
\hline \multicolumn{4}{|l|}{ Values are the mean $\pm S D$} \\
\hline \multicolumn{4}{|c|}{$p$-values for the differences in the means between the two groups } \\
\hline \multicolumn{4}{|c|}{$\begin{array}{l}\Delta=\text { difference between postexercise and baseline values; Index } 2 \text { denotes postexercise, and index } 1 \\
\text { baseline values; } \mathrm{E}=\mathrm{E} \text {-wave peak velocity; } \mathrm{A}=\mathrm{A}-\mathrm{wave} \text { peak velocity; } \mathrm{DR}=\mathrm{E} \text {-wave deceleration rate; HF } \\
=\text { heart rate; Peak HR = HR at cessation of exercise; TIME = time of obtaining Doppler variables } \\
\text { measured from the cessation of exercise. }\end{array}$} \\
\hline
\end{tabular}

Multiple linear regression was calculated to predict $\triangle E$ and $\triangle D R$ from age, sex, peak $H R, \Delta H R$, exercise duration, IR (IR = 0 for nonischemics, and IR = 1 for ischemics), TIME, and the TIME*IR interaction. Table 3 presents a summary of this regression analysis. Forward selection criteria were applied with IR, TIME, and TIME*IR as an initial set of predictors. Except for age, none of the other independent variables introduced one by one and in various combinations contributed significantly on their own. 
Table 3

Summary of Regression Analysis for Variables Predicting Changes in E and DR

\begin{tabular}{|c|c|c|}
\hline & $\Delta \mathrm{E}$ & $\Delta \mathrm{DR}$ \\
\hline Age & $\mathrm{NS} \Uparrow(p=0.065)$ & $\Uparrow$ \\
\hline IR & $N S \Downarrow(p=0.242)$ & $\mathrm{NS} \Downarrow(p=0.206)$ \\
\hline TIME & $\Downarrow \Downarrow \Downarrow$ & $\Downarrow \Downarrow$ \\
\hline TIME*IR & $\Uparrow$ & $\Uparrow$ \\
\hline Adjusted $\mathrm{R}^{2}$ & 0.162 & 0.175 \\
\hline \multicolumn{3}{|c|}{ Directions of arrows indicate direction of association (upward means positive) } \\
\hline \multicolumn{3}{|c|}{$\Uparrow: p<0.05 ; \Uparrow \Uparrow: p<0.01 ; \Uparrow \Uparrow \Uparrow: p<0.001$} \\
\hline \multicolumn{3}{|c|}{ NS $=$ nonsignificant $(p>0.05)$} \\
\hline \multicolumn{3}{|c|}{$\begin{array}{l}\mathrm{IR}=\text { ischemic response: for nonischemics } \mathrm{IR}=0 \text {, and for ischemics } \mathrm{IR}=1 ; \mathrm{TIME}=\text { time of obtainin } \\
\text { Doppler variables measured from the cessation of exercise; } R^{2}=\text { coefficient of determination; } \Delta= \\
\text { difference between postexercise and baseline values; } \mathrm{E}=\mathrm{E} \text {-wave peak velocity; and } \mathrm{DR}=\mathrm{E} \text {-wave } \\
\text { deceleration rate. }\end{array}$} \\
\hline
\end{tabular}

This model showed a marginally significant influence of age on $\Delta \mathrm{E}[F(4,99)=5.972$, sig. $F<0.001$, coeff. $0.336, p=0.065,95 \% \mathrm{Cl}:-0.021-0.694]$. Age was a significant predictor of $\Delta \mathrm{DR}[F(4,99)=6.479$, sig. $F<$ 0.001 , coeff. $3.989, p=0.038,95 \% \mathrm{Cl}: 0.232-7.745]$. The main effect of ischemia on $\Delta \mathrm{E}$ and $\Delta \mathrm{DR}$ was not significant. The main effects of TIME on $\triangle \mathrm{DR}[F(4,99)=6.479$, sig. $F<0.001$, coeff. $-80.445, p=$ $0.001,95 \% \mathrm{Cl}:-125.319$ to -35.571$]$ and on $\Delta \mathrm{E}[F(4,99)=5.972$, sig. $F<0.001$, coeff. $-7.988, p<0.001$, $95 \% \mathrm{Cl}:-12.262$ to -3.714$]$ were statistically significant. The values of $\Delta \mathrm{E}$ and $\Delta \mathrm{DR}$ obtained later were lower than those obtained earlier.

There was no correlation between IR and $\operatorname{TIME}(r=0.06, p=0.57)$, and the frequency distribution of ischemics was not statistically different between and within groups of TIME $(1-6 \mathrm{~min})[F(5,98)=1.49, p$ $=0.20)$ ]. There was no bias in collecting data regarding TIME between ischemics and nonischemics.

The TIME*IR interaction was statistically significant for $\Delta \mathrm{DR}[F(4,99)=6.479$, sig. $F<0.001$, coeff. 90.473, $p=0.025,95 \% \mathrm{Cl}: 11.832-169.113]$ and for $\Delta \mathrm{E}[F(4.99)=5.972$; sig. $F<0.001 ;$ coeff. $7.799 ; p=$ $0.041,95 \% \mathrm{Cl}: 0.309-15.289]$. The effect of IR on the values of $\Delta \mathrm{E}$ and $\Delta \mathrm{DR}$ relied on the time after cessation of exercise at which data were collected.

To determine the time course of $\Delta E=E_{2}-E_{1}$ and $\triangle D R=D R_{2}-D R_{1}$ after the exercise, multiple linear regressions were performed to predict $\triangle E$ and $\triangle D R$ from the IR, TIME, and TIME*IR interaction as predictors. The general form of the regression function was as follows:

$\mathrm{Y}=\mathrm{C}_{0}+\mathrm{C}_{1} \cdot\left(\mathrm{TIME}-\mathrm{T}_{\text {shift }}\right)+\mathrm{C}_{2} \cdot \mathrm{IR}+\mathrm{C}_{3} \cdot \mathrm{IR} \cdot\left(\mathrm{TIME}-\mathrm{T}_{\text {shift }}\right)$ 
where $\mathrm{Y}$ represented either $\Delta \mathrm{E}$ or $\Delta \mathrm{DR}, \mathrm{T}_{\text {shift }}$ is the time shift $\left(\mathrm{T}_{\text {shift }}=0\right.$ denotes linear regression with respect to the end of the exercise, $T_{\text {shift }}=1$ min denotes linear regression with respect to the time coordinate having zero in the first minute, continuing similarly for later times). The outcome of the multiple regression model for nonischemics $(I R=0)$ was calculated according to

$$
\mathrm{Y}_{\text {nonischemic }}=\left[\mathrm{C}_{0^{--}} \mathrm{C}_{1} \cdot \mathrm{T}_{\text {shift }}\right]+\mathrm{C}_{1} \cdot \mathrm{TIME}
$$

where, coefficient $\mathrm{C}_{1}$ denotes the slope.

For ischemics $(I R=1)$, the outcome is

$$
\mathrm{Y}_{\text {ischemics }}=\left[\mathrm{C}_{0}-\mathrm{C}_{1} \cdot \mathrm{T}_{\text {shift }}+\mathrm{C}_{2}-\mathrm{C}_{3} \cdot \mathrm{T}_{\text {shift }}\right]+\left[\mathrm{C}_{1}+\mathrm{C}_{3}\right] \cdot \mathrm{TIME}
$$

where the slope is $\mathrm{C}_{1}+\mathrm{C}_{3}$.

Note that the intercept is a function of $T_{\text {shift }}$ and IR: it changes from $\left[\mathrm{C}_{0}--\mathrm{C}_{1} \cdot \mathrm{T}_{\text {shift }}\right]$ for nonischemics to $\left[\mathrm{C}_{0}--\mathrm{C}_{1} \cdot \mathrm{T}_{\text {shift }}+\mathrm{C}_{2}--\mathrm{C}_{3} \cdot \mathrm{T}_{\text {shift }}\right]$ for ischemics.

Figures 2 and 3 show slopes for the group of ischemics (coefficients $C_{1}+C_{3}$ ) and nonischemics (coefficient $\mathrm{C}_{1}$ ).

The slopes of $\triangle \mathrm{E}$ or $\triangle \mathrm{DR}$ in ischemic subjects were not significantly different from zero. Contrarily, slopes of $\Delta \mathrm{E}(p<0.001)$ and $\triangle \mathrm{DR}(p=0.001)$ in the nonischemic subjects were significantly different from zero and negative. Our model showed that there was a significant IR*TIME interactive effect on $\triangle \mathrm{E}$ (adj. $R^{2}=$ $0.14, F(3,100)=6.64$, sig., $F<0.001$, coeff. 8.1, $p=0.037,95 \% \mathrm{Cl}: 0.51-15.66)$ and $\Delta \mathrm{DR}$ [adj. $R^{2}=0.15$, $F(3,100)=6.92$, sig. $F<0.001$, coeff. $93.8, p=0.022,95 \% \mathrm{Cl}: 13.9-173.7]$. Consequently, regression slopes were significantly different between the ischemic and nonischemic subjects (coefficient C3 for the $I R^{\star} T I M E$ interactive effect). Figure 2 shows the measured $\triangle E$ as a function of TIME and IR and the regression lines for the ischemic and nonischemic subjects, and Figure 3 shows the same for $\triangle D R$. At $\mathrm{T}_{\text {shift }}=0$, the intercepts of the regression lines of $\Delta \mathrm{E}$ and $\triangle \mathrm{DR}$ were not significantly different between the two groups. As shown by the regression lines for the ischemic group, the values of $\Delta E$ and $\triangle D R$ remain constant within the first 6 min, whereas in the nonischemic group, $E$ and $D R$ tend to return to the baseline values. Consequently, the differences in $\triangle E$ and $\triangle D R$ between the two groups increased in TIME; hence, the question was at what time did these differences become significant, i.e., the time at which the simple main effect of IR became relevant.

Table 4 presents the $p$-values for the simple main effect of IR on $\Delta \mathrm{E}$ and $\Delta \mathrm{DR}$, calculated at different $\mathrm{T}_{\text {shift }}$ values. The results indicated that until the third minute, the effect of ischemia was not significant. At $\geq 3$ min, positive associations of ischemia with $\triangle \mathrm{DR}$ and $\Delta \mathrm{E}$ were highly significant, which means that the 
values of these variables were significantly higher in the ischemic subjects.

Table 4

P-values for the Simple Main Effect of Ischemia on $\Delta \mathrm{E}$ and $\Delta \mathrm{DR}$ as a Function of $\mathrm{T}_{\text {shift }}$

\begin{tabular}{|llllllll|}
\hline $\mathrm{T}_{\text {shift }}$ min & $\mathbf{0}$ & $\mathbf{1}$ & $\mathbf{2}$ & $\mathbf{3}$ & $\mathbf{4}$ & $\mathbf{5}$ & $\mathbf{6}$ \\
\hline$\Delta \mathrm{E}, \mathrm{cm} / \mathrm{s}$ & 0.271 & 0.532 & 0.651 & $\mathbf{0 . 0 1 2}$ & $\mathbf{0 . 0 0 1}$ & $\mathbf{0 . 0 0 2}$ & $\mathbf{0 . 0 0 5}$ \\
\hline$\Delta \mathrm{DR}, \mathrm{cm} / \mathrm{s}^{2}$ & 0.236 & 0.516 & 0.578 & $\mathbf{0 . 0 0 5}$ & $\mathbf{0 . 0 0 0}$ & $\mathbf{0 . 0 0 1}$ & $\mathbf{0 . 0 0 2}$ \\
\hline
\end{tabular}

$\mathrm{T}_{\text {shift }}=$ time shift; $\Delta=$ difference between postexercise and baseline values; $\mathrm{E}$ = E-wave peak velocity; and $\mathrm{DR}=\mathrm{E}$-wave deceleration rate.

\section{Discussion}

The purpose of this clinical study was to examine whether DMIPs after exercise were more restrictive in subjects with induced ischemia compared to those without ischemia. The results indicate that there is not an unambiguous answer to that question.

The key finding from our results is that $\triangle E$ and $D R$ in the ischemic and nonischemic groups have divergent time courses after the exercise, which has two significant consequences. The first is that $\Delta \mathrm{E}$ and DR do not differ at exercise cessation between the two groups. The second is that the influence of exercise-induced ischemia on $\triangle E$ and $D R$ is significant only at $\geq 3$ minutes after the exercise. In the ischemic group, $\triangle E$ and $\triangle D R$ are constant in the first 6 min after exercise, whereas $E$ and $D R$ tend to their basal values in the same period in the nonischemic subjects.

TIME and ischemia influenced $\triangle \mathrm{E}$ and $\triangle \mathrm{DR}$, and because of their significant interaction, establishing a conclusion about the influence of ischemia on $\triangle E$ and $\triangle D R$ without consideration of TIME is inappropriate. Whether ischemia is associated with changes in $\triangle E$ and $\triangle D R$ depends on TIME, and conversely, whether TIME correlates with $\triangle E$ and $\triangle D R$ depends on ischemia. For data obtained within the first 2 min after the exercise, $\Delta E$ and $\triangle D R$ were the same in both groups, so IR was not a predictor of changes. On the contrary, for data obtained at $3 \mathrm{~min}$ and after that, the $\Delta \mathrm{E}$ and $\Delta \mathrm{DR}$ were significantly higher in the ischemic group, so IR became a predictor of changes.

DMIP changes follow the changes in AVPGs. Consequently, AVPGs should be the same in the first two minutes after exercise in persons with and without IR. Although, it is reasonable to assume that changes in relevant physiological variables and the proportional effect of each on AVPGs differed between the two groups. It is important to emphasize that AVPG can occur at any pressure, so it indicates nothing about pressure levels in the LA and LV. 
After exercise, there was a gradual decrease in cardiac output (CO) in both groups because of reduced body metabolism and oxygen demand. In patients without ischemia, there was a gradual return of $E, D R$ (Figures 2 and 3), and presumably AVPG and all relevant physiological variables (relaxation rate, filling volumes, and apparent LV stiffness) to baseline values within $6 \mathrm{~min}$. Conversely, although the patients with ischemia restored the baseline coronary blood flow, postischemic diastolic dysfunction has been persistent due to processes at the molecular level (ATP depletion, calcium overload, and oxyradical formation) [6-8]. Consequently, high LV stiffness persisted with elevated LA pressure, and $\triangle E$ and $\triangle D R$ remained constant in the observed time after TSE.

We can conceptualize these findings into three hypothetical paradigmatic responses to exercise at their extremes: 1. normal response with an increase in the relaxation rate without an increase in LA pressure, 2. diastolic dysfunction without ischemia with a blunted increase in the relaxation rate, volume induced increase in apparent LV stiffness that leads to high LA pressure, 3. ischemia-induced diastolic dysfunction with a blunted increase in the relaxation rate, and high LA pressure due to increase in LV stiffness.

An initial study on the influence of exercise-induced ischemia on the diastolic function showed that in ischemics, DMIP became more restrictive [15]. Numerous studies afterward corroborated these findings. However, none of them took into consideration the importance of the time of obtaining images after exercise cessation on DMIP. It is interesting how this observation has escaped for years the attention of the researchers' community. The interpretation of the results of this study is founded on a clear physical and physiological concept. We created a new paradigm with a pathophysiological rationale based on the fact that there is a persistent high LV stiffness after cessation of exercise in patients who develop ischemia because of postischemic diastolic dysfunction. E and DR of these patients will not tend toward baseline values in the first few minutes after exercise, which is opposite to the tendency observed in patients with no ischemia.

We recommend expressing the Doppler variable values in diastolic stress echocardiographic studies by referring to the time elapsed since exercise cessation.

\section{Limitations}

We included a relatively small number of participants. The diagnosis of ischemia via stress echocardiography is a subjective assessment, estimated visually and at risk of false positive and negative results and interobserver variability.

\section{Conclusion}

In this study, we measured baseline and postexercise values of E and DR. Postexercise values were measured at a known TIME. We statistically analyzed $\triangle E$ and $\triangle D R$ in relation to TIME, IR, and their interaction. There were significant effects of the interaction of IR and TIME on $\triangle E$ and $\triangle D R$. After the cessation of exercise, $\Delta \mathrm{E}$ and $\Delta \mathrm{DR}$ in nonischemic subjects, but not in ischemic subjects, quickly tend to 
zero. The differences in $\Delta E$ and $\triangle D R$ between the two groups only became significant for TIME of $\geq 3$ min. At the time of exercise cessation, the values of $\Delta E$ and $\triangle D R$ (taken from the regression lines) were not significantly different between the patients with and without IR.

This divergent response might be promising for detecting diastolic dysfunction caused by ischemia.

\section{Declarations}

\section{Funding:}

The authors did not receive support from any organization for the submitted work.

\section{Financial and non-financial interests}

The authors have no relevant financial or non-financial interests to disclose.

\section{References}

1. Appleton CP, Jensen JL, Hatle LK, Oh JK (1997) Doppler evaluation of left and right ventricular diastolic function: a technical guide for obtaining optimal flow velocity recordings. J Am Soc Echocardiogr10:271-292 doi:10.1016/s0894-7317(97)70063-4

2. Bell SP, Fabian J, LeWinter MM (1998) Effects of dobutamine on left ventricular restoring forces. Am J Physiol 275:H190-H194 doi:10.1152/ajpheart.1998.275.1.H190

3. Braunwald E (1997) Heart Disease: A Textbook of Cardiovascular Medicine. 5th ed. Saunders, Philadelphia

4. Charlat ML, O’Neill PG, Hartley CJ, Roberts R, Bolli R (1989) Prolonged abnormalities of left ventricular diastolic wall thinning in the "stunned" myocardium in conscious dogs: time course and relation to systolic function. J Am Coll Cardiol 13:185-194 doi:10.1016/0735-1097(89)90569-x

5. Choong CY, Abascal VM, Thomas JD, Guerrero JL, McGlew S, Weyman AE (1988) Combined influence of ventricular loading and relaxation on the transmitral flow velocity profile in dogs measured by Doppler echocardiography. Circulation 78:672-683 doi:10.1161/01.cir.78.3.672

6. Courtois M, Vered Z, Barzilai B, Ricciotti NA, Pérez JE, Ludbrook PA (1988) The transmitral pressureflow velocity relation. Effect of abrupt preload reduction. Circulation 78:1459-1468 doi:10.1161/01.cir.78.6.1459

7. Eisman AS, Shah RV, Dhakal BP, Pappagianopoulos PP, Wooster L, Bailey C, Cunningham TF, Hardin KM, Baggish AL, Ho JE, Malhotra R, Lewis GD (2018) Pulmonary capillary wedge pressure patterns during exercise predict exercise capacity and incident heart failure. Circulation Heart Failure 11:e004750 doi:10.1161/CIRCHEARTFAILURE.117.004750

8. Fraites TJ Jr, Saeki A, Kass DA (1997) Effect of altering filling pattern on diastolic pressure-volume curve. Circulation 96:4408-4414 doi:10.1161/01.CIR.96.12.4408 
9. Ishii K, Imai M, Suyama T, Maenaka M, Nagai T, Kawanami M, Seino Y (2009) Exercise-induced postischemic left ventricular delayed relaxation or diastolic stunning: is it a reliable marker in detecting coronary artery disease? J Am Coll Cardiol 53:698-705 doi:10.1016/j.jacc.2008.09.057

10. Kass DA, Bronzwaer JG, Paulus WJ (2004) What mechanisms underlie diastolic dysfunction in heart failure? Circ Res 94:1533-1542 doi:10.1161/01.RES.0000129254.25507.d6

11. King LM, Boucher F, Opie LH (1995) Coronary flow and glucose delivery as determinants of contracture in the ischemic myocardium. J Mol Cell Cardiol 27:701-720 doi:10.1016/s00222828(08)80061-2

12. Kohmoto O, Barry WH (1989) Mechanism of protective effects of Ca++ channel blockers on energy deprivation contracture in cultured ventricular myocytes. J Pharmacol Exp Ther248:871-878

13. Nikolic SD, Tamura K, Tamura T, Dahm M, Frater RW, Yellin EL (1990) Diastolic viscous properties of the intact canine left ventricle. Circ Res 67:352-359 doi:10.1161/01.res.67.2.352

14. Nikolic S, Yellin EL, Tamura K, Tamura T, Frater RW (1990) Effect of early diastolic loading on myocardial relaxation in the intact canine left ventricle. Circ Res 66:1217-1226 doi:10.1161/01.res.66.5.1217

15. Nonogi H, Hess OM, Bortone AS, Ritter M, Carroll JD, Krayenbuehl HP (1989) Left ventricular pressurelength relation during exercise-induced ischemia. J Am Coll Cardiol 13:1062-1070 doi:10.1016/07351097(89)90261-1

16. Presti CF, Walling AD, Montemayor I, Campbell JM, Crawford MH (1991) Influence of exerciseinduced myocardial ischemia on the pattern of left ventricular diastolic filling: a Doppler echocardiographic study. J Am Coll Cardiol 18:75-82. doi:10.1016/s0735-1097(10)80221-9

17. Quick CM, Berger DS, Noordergraaf A (1998,) Apparent arterial compliance. Am J Physiol 274:H1393H1403 doi:10.1152/ajpheart.1998.274.4.H1393

18. Quick CM, Young WL, Noordergraaf A (2001) Infinite number of solutions to the hemodynamic inverse problem. Am J Physiol Heart Circ Physiol 280:H1472- H1479 doi:10.1152/ajpheart.2001.280.4.H1472

19. Reddy YNV, El-Sabbagh A, Nishimura RA (2018) Comparing pulmonary arterial wedge pressure and left ventricular end diastolic pressure for assessment of left-sided filling pressures. JAMA Cardiology 3:453-454 doi:10.1001/jamacardio.2018.0318

20. Roger VL, Pellikka PA, Oh JK, Miller FA, Seward JB, Tajik AJ (1995) Stress echocardiography. Part I. Exercise echocardiography: techniques, implementation, clinical applications, and correlations. Mayo Clin Proc 70:5-15. doi:10.1016/S0025-6196(11)64659-4

21. Shintani H, Glantz SA (1994) Influence of filling on left ventricular diastolic pressure-volume curve during pacing ischemia in dogs. Am J Physiol 266:H1373- $\mathrm{H} 1385$ doi:10.1152/ajpheart.1994.266.4.H1373

22. Solomon SB, Nikolic SD, Glantz SA, Yellin EL (1998) Left ventricular diastolic function of remodeled myocardium in dogs with pacing-induced heart failure. Am J Physiol 274:H945-H954 doi:10.1152/ajpheart.1998.274.3.H945 
23. Thomas JD, Choong CY, Flachskampf FA, Weyman AE (1990) Analysis of the early transmitral Doppler velocity curve: effect of primary physiologic changes and compensatory preload adjustment. J Am Coll Cardiol 16:644-655 doi:10.1016/0735-1097(90)90356-t

24. Thomas JD, Newell JB, Choong CY, Weyman AE (1991) Physical and physiological determinants of transmitral velocity: numerical analysis. Am J Physiol 260:H1718- H1731 doi:10.1152/ajpheart.1991.260.5.H1718

25. Thomas JD, Weyman AE (1992) Numerical modeling of ventricular filling. Ann Biomed Eng 20:19-39 doi:10.1007/bf02368504

26. Van de Werf F, Minten J, Carmeliet P, De Geest H, Kesteloot $H$ (1984) The genesis of the third and fourth heart sounds. A pressure-flow study in dogs. J Clin Invest 73:1400-1407 doi:10.1172/JCl111344

27. Wolsk E, Bakkestrøm R, Thomsen JH, Balling L, Andersen MJ, Dahl JS, Hassager C, Moller JE, Gustafsson $F$ (2017) The influence of age on hemodynamic parameters during rest and exercise in healthy individuals. JACC Heart Fail 5:337-346 doi:10.1016/j.jchf.2016.10.012

28. Yamamoto K, Masuyama T, Tanouchi J, Uematsu M, Doi Y, Mano T, Hori M, Tada M, Kamada T (1993) Peak early diastolic filling velocity may decrease with preload augmentation: effect of concomitant increase in the rate of left atrial pressure drop in early diastole. J Am Soc Echocardiogr 6:245-254 doi:10.1016/s0894-7317(14)80060-6

\section{Figures}

\section{Figure 1}

\section{Doppler mitral inflow pattern}

\section{Figure 2}

\section{Regression slopes of $\Delta E$ as a function of TIME and ischemia}

$\Delta \mathrm{E}$ is the difference between the E-wave peak velocities after exercise (taken at TIME after cessation of exercise) and at baseline. Blue circles denote data for the nonischemic group, and red triangles denote data for the ischemic group. The slope of $\Delta \mathrm{E}$ in nonischemics but not in ischemics is significantly different from zero. The difference in the slopes of the two groups is significant $(p=0.037)$. 


\section{Figure 3}

\section{Regression slopes of $\triangle D R$ as a function of TIME and ischemia}

$\triangle \mathrm{DR}$ is the difference between the E-wave deceleration rates after exercise (taken at TIME after cessation of exercise) and at baseline. Blue circles denote data for the nonischemic group, and red triangles denote data for the ischemic group. The slope of $\triangle D R$ in nonischemics but not in ischemics is significantly different from zero. The difference in the slopes of the two groups is significant $(p=0.022)$.

\section{Supplementary Files}

This is a list of supplementary files associated with this preprint. Click to download.

- graphicalabstract.docx 